\title{
The effects of positioning and pursed-lip breathing exercise on dyspnea and anxiety status in patients with chronic obstructive pulmonary disease
}

\author{
Salwa A. Mohamed* \\ Medical Surgical Nursing Department, Faculty of Nursing, Fayoum University, Fayoum, Egypt
}

Received: November 12, 2018

Accepted: January 4, 2019

Online Published: February 25, 2019

DOI: $10.5430 /$ jnep.v9n6p41

URL: https://doi.org/10.5430/jnep.v9n6p41

\begin{abstract}
Background and objective: Chronic obstructive pulmonary disease (COPD) remains a significant burden for health. It is one of the most common respiratory disease and leads to limitation of airflow as well as deteriorating health status. The aim of the study was to determine the effects of positioning and pursed lip breathing exercise on dyspnea and anxiety status in patients with chronic obstructive pulmonary disease.

Methods: The study was carried in the outpatient clinics in Mansoura University Hospital \& Chest Hospital at Mansoura region, utilizing a quasi-experimental study design on sixty patients diagnosed COPD. Participation was randomized into both groups (study group and control group). Pretest, posttest and follow-up evaluation was done using Dyspnea Assessment Scale, Anxiety Assessment Scale and Demographic and Medical History Questionnaires (MHQ). The researcher established exercise program aimed at effecting dyspnea and anxiety in chronic obstructive pulmonary disease patients to help improve breathing and control anxiety. The research was accomplished over four steps namely assessment, planning, implementation and evaluation. Each patient was evaluated at baseline, immediately and three months after implementation of program.

Results: There were statistically significant improvements after intervention of program on dyspnea symptoms and anxiety status at post and follow-up test $(p<.05)$. There was a statistically significant improvement in temperature (T), heart rate (HR), blood pressure (BP) and respiratory rate (RR) throughout study $(p<.05)$ after intervention. Also there are positive relation between anxiety and dyspnea after intervention.

Conclusions: Developing breathing technique and forward leaning position in COPD patients help to improve physiological outcomes, dyspnea symptoms and anxiety status after implementing of program. It is recommended to implement exercise training program as a part of treatment by health professionals in the clinical setting.
\end{abstract}

Key Words: Chronic obstructive pulmonary disease, Dyspnea, Anxiety, Dyspnea positioning, Pursed lip breathing exercise

\section{INTRODUCTION}

Chronic obstructive pulmonary disease (COPD) is a preventable and treatable disease. It is characterized by irreversible airflow obstruction. The obstruction is generally progressive and associated with chronic inflammatory re- sponse in the airways and the lung to noxious particles or gases. ${ }^{[1]}$ There is a progressive pulmonary function impairment that leads to poor exercise tolerance and in the critical conditions, some patients may require supplemental oxygen or mechanical ventilation (MV). ${ }^{[2]}$

\footnotetext{
*Correspondence: Salwa A. Mohamed; Email: sam15@Fayoum.edu.eg; Address: Medical Surgical Nursing Department, Faculty of Nursing, Fayoum University, Fayoum, Egypt.
} 
Chronic obstructive pulmonary disease is a progressive lifethreatening lung disease that causes breathlessness. COPD is an umbrella term that implicate two more commonly lung diseases such as chronic bronchitis and emphysema which were characterized by persistent airflow limitation ${ }^{[3,4]}$ and reduced blood oxygenation as well as respiratory acidosis. ${ }^{[5]}$ COPD is a major cause of morbidity and mortality in the population. ${ }^{[6]}$

Patients with chronic obstructive pulmonary may suffer other factors, however such as breathlessness, fatigue, ongoing cough, functional limitation and general worsening of quality of life. So, self-management interventions should be efficient method to enhance care of patients, psychosocial support, improve breathing, develop skills to burden symptoms and lessen progressive of the disease. ${ }^{[7,8]}$

Dyspnea is the most common and distressing symptom of pulmonary disease. It is sensation of disability to get air lead to uncomfortable breathing, extremely on a regular basis. Dyspnea is a very common presenting complaint of patient, can be attributable to organic or psychogenic factors. On the other hand, dyspnea can be a manifestation of underlying anxiety disorder. ${ }^{[9,10]}$ Anxiety is also a significantly psychological comorbidity among chronic obstructive pulmonary disease and is often associated with increased disability, negative appraisal of dyspnea and decreased adherence to the treatment. Few studies have found anxiety can cause shortness of breath as a direct and immediate symptom chronic obstructive pulmonary disease COPD, which evidence with less functional status and re-hospitalizations. ${ }^{[11-13]}$

Dyspnea is complaint of difficult, labored, or uncomfortable breathing. Anxiety and dyspnea, two major symptoms associated with COPD. ${ }^{[14]}$ However, dyspnea is also a stronger association with negative health-related quality of life especially in patients with respiratory disease. Thus, patient education and training important planning to minimize burden of symptoms and better quality of life through improve the patient outcome. ${ }^{[15]}$

The major goal of management and treatment for patients with COPD is improved of inspiratory muscle functions (IMF) and reduced shortness of breathing. Breathing controlled training and a sitting posture have been evidenced as therapeutic interventions in patients with chronic obstructive pulmonary disease to alleviate breathlessness and improve ventilation. ${ }^{[16]}$ Breathing controlled training (BCT) usually includes breathing exercises (BEs), inhaler technique, meditation, body positions (BPs), relaxation techniques (yoga) and pursed- lip breathing (PLB). ${ }^{[17]}$

Pursed lip breathing is a breathing technique used as part of treatment for COPD. It is frequently used to alleviate dyspnea, reduces the respiratory rate, help restore diaphragmatic function and reduce anxiety disorders. ${ }^{[18]}$ One study on effectiveness of pursed- lip breathing on anxiety $\&$ depression in COPD patient. They revealed significantly improved dyspnea, anxiety, and mobility. ${ }^{[19]} \mathrm{McGe}^{[20]}$ investigated that controlled breathing techniques such as pursed-lip breathing help to reduce respirations, preventing airway collapse, burden symptoms of anxiety and easing alveolar ventilation as well as improvement breathlessness can be achieved by forward leaning position.

Nurses have an important role in enhancing the care of patients through education and training approaches, which will help them to improve the practices and knowledge about disease and management. ${ }^{[21]}$ Also nursing care is based on the principle of the preservation, promotion, and restoration of health. Therapeutic Patient Education (TPE) permits people with chronic diseases to acquired knowledge and skill related to management of disease, behavior change, energy conservation, and psychosocial interventions. ${ }^{[22]}$ Improving awareness, knowledge and skills regarding COPD management leading to decrease of dyspnea and better patient outcomes. ${ }^{[23]}$

\subsection{Operational definition}

Pursed lip breathing: It is a breathing technique that consists of exhaling slowly through nose and then exhaling against pursed lips; to eases breathing and to prevent small airway collapse.

Positioning: Dyspnea position (forward leaning positioning) is to stand erect, leaning slightly forward, and let your shoulders and arms hang slightly forward to help improve respiratory rate and reducing breathlessness.

Chronic obstructive pulmonary disease: It is a group of progressive lung diseases characterized by chronic, partial or complete obstruction to the airflow at any level from trachea to the smallest airways resulting in a slowed rate of exhalation.

\subsection{Significance of the study}

COPD is a worldwide health problem that affects over fourteen million people at the United States (US). It is considered the fifth leading causes of disability and third most common causes of death in adults by $2020 .{ }^{[24]}$ Hence, this could assist nurses to planning and implementing strategies for applicable effective care to adults' patients diagnosed with COPD and manage stressors that can exacerbate the disease. The evidence recommended of multimodal progressive relaxation technique such as breathing exercise, yoga, positioning and other else in order to increase relaxation and control psycho- 
logical reaction thereby reducing the mortality, morbidity rate in patients and also greatly decrease health care costs and promote patient quality of life.

\section{SUBJECTS AND METHODS}

\subsection{Aim of the study}

The aim of this study was to evaluate the effects of positioning and pursed lip breathing exercise on dyspnea and anxiety status in patients with chronic obstructive pulmonary disease.

\subsection{Research hypotheses}

H.1: Patients who practiced lips pursed breathing exercise and body positioning have significantly less dyspnea than would those did not.

H.2: Patients who practiced body positioning and pursed lips breathing (PLB) have statistical significantly less anxiety level after implementation than would those didn't used.

H.3: Patients' expected physiological outcomes such vital signs and will be significantly within normal value after implementation of the program.

\subsection{Study design and setting}

The study was conducted in the outpatient in Mansoura University Hospital (MUH) \& Chest Hospital at Mansoura Region. A randomized controlled design was executed with a study and control groups. Pre, post and follow-up test assessments was used for this study.

\subsection{Subjects}

A convenience sample of sixty patients with COPD who agreeable to participate in this program and met the following inclusive criteria were included in the research: adult (eighteen years or older patient), mild and moderate COPD, patients free from any chronic diseases. Also patients who don't receive any related educational program. Sample were assigned to two groups, study group $(\mathrm{n}=30)$ and control group $(\mathrm{n}=30)$ (see Figure 1).

\subsection{Tools}

Data collection tools consisted of four tools:

\subsubsection{Demographic data and medical history question- naires}

It was included sex, age, educational status, occupation, and marital status. The medical information form included the duration of illness and exposure for pollution, smoking, previous hospital admission and pain control analgesia used.

\subsubsection{Dyspnea assessment scale}

Dyspnea of the patients in this study was measured using the Modified Borg Scale (MBS) developed by Borg. ${ }^{[25]}$ It is utilized for the estimation of disability due to dyspnea during daily activities, with a Likert scale ranging from $0-10$ item scales, (0) no breathlessness at all and (10) maximum breathlessness. The scores summed up and mean score for this scale.

\subsubsection{Anxiety assessment scale}

Anxiety status in this study was measured using the Zung Self-Rating Anxiety Scale (SAS) adopted by Zung given. ${ }^{[26]}$ It designed to measure anxiety levels based on four subscales that tap manifestations of anxiety status: cognitive, autonomic, motor and central nervous system (CNS). It included 20 items covering psychological condition. Each response to all items of this tool were on a 4-pointLikert scale 0 (not present) to 4 (severe). The total scores ranged from 20-80 and category were 20-44 normal range, 45-59 mild to moderate anxiety levels, 60-74 marked to sever anxiety levels and 75-80 extremely anxiety levels.

\subsubsection{The physical assessment sheet}

This sheet was prepared to estimate patient physical assessment based on literature review about chronic obstructive pulmonary disease. It contains pulse, temperature, respiration rate, blood pressure and weight.

\subsection{Validity and reliability}

Validity were done for tools by five experts from nursing and medical to check content comprehensiveness, relevancy and minor modifications were done. The reliability of tools $(2,3)$ was estimated using the internal consistency. It found that Chronbach's Alpha reliability coefficients was 0.972 \& 0.934 .

\subsection{Pilot study}

A pilot study was conducted on 6 patients to test the clarity and applicability of the study tools.

\subsection{Human right and ethical consideration}

Permission to conduct the study was obtained from the authorities of hospitals. The purpose and nature of the study explained for patients, and then an informed consent was acquired from participants who agreed to participate in the study. The researcher asserted that participation in the study is completely voluntary and confidentiality was assured through coding the data.

\subsection{Field work}

The study initiate from October 2016 to June 2017. It's achieved through 4 stages: assessment, planning, implementation and evaluation.

\subsubsection{Assessment phase}

Through this stage, the researcher explaining the purpose of the study and obtaining their consents from patients. also 
gather patient's data to define learning needs and ability to the study trial was interviewed using Demographic Data and design the appropriate nursing program. Every newly di- Medical History Questionnaires, Dyspnea Assessment Scale, agnosed chronic obstructive pulmonary patient recruited in Anxiety Assessment Scale, The Physical Assessment Sheet.

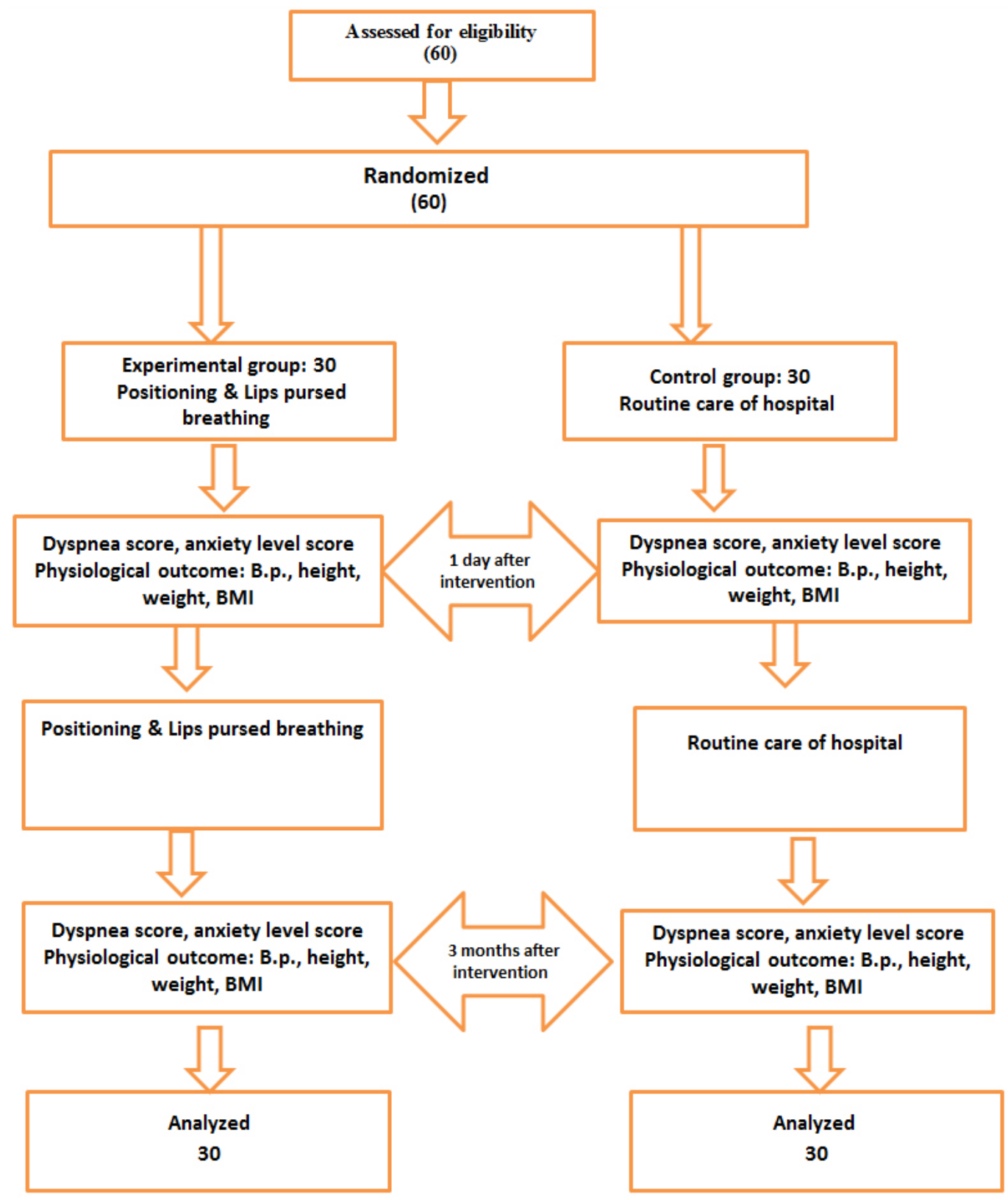

Figure 1. Flow chart

\subsubsection{Planning phase}

During this phases, the exercise training program was prepared based on the results of the assessment and related literature. The exercise training were designed to get better patient's knowledge and practice about COPD management and control symptoms of disease. Exercise training was prepared by the researcher and designed in an Arabic language. It includes the guidelines handout and audiovisual materi- als about intervention (relaxation techniques, lips pursed breathing, and positioning). Illustrated handout included the following: definition COPD, etiology, signs and symptoms, complication, diet, nursing intervention such as nonpharmacological intervention such breathing exercise and positioning and constant follow up at chest clinic. Also the content validity of the intervention was revised by expertize from specialty of nursing and medicine. 


\subsubsection{Implementation phase}

The aim of this phase was to given the nursing intervention for each patient individually. The study subjects were exposed to the intervention through 6 sequential sessions over three weeks ( 2 session theory \& 4 sessions practical). Each session proceeds around 30-45 minutes; each patient met two times/week at morning shift. Theoretical session divided into section (section one about knowledge and section two give conclusion and summary). During these session using PowerPoint, figure, lectures and so on.

As regards the practical session, it rounded 4 session according patient and family needs for illustrated skills, every session nearly 45 minutes during it demonstration and re-demonstration learned for patients and/or relative about breathing exercise and forward lean positioning. In addition to, the importance of physical activities were explained for participants and also give chance for patient ask and discussion. However, the investigator had periodical communicate with the patients throughout of telephone for refreshing the provided knowledge, and answer any questions.

\subsubsection{Evaluation phase}

During evaluation phase, the assessment occurred three times with every patient during this study: $\mathrm{T} 1$ was at the first to collect demographic and medical data, anxiety assessment sheet, breathlessness assessment, physical outcome data from study groups as baseline data, T2: post implementation of exercise program to detect the influence training program on knowledge, skill and physical outcomes. Finally, T3 was done after three month to follow up patient response using the same tools prior within study.

\subsection{Statistical data}

Variance is computed, statistical analysis were well done utilizing SPSS version (16.0). Data were offered in the shape of frequencies (F) and percentages (\%), and means and standard deviations (SD). C2 test using to compare categorical data the correlation was used for estimating relationships through quantitative variables and multiple logistic regression analysis was used. $P$-value is less than .05 that statistical significant.

\section{RESUltS}

Table 1 represents that demographic characteristic of patients group. It display that $53.3 \%$ of participants have age $>56$ years old in the study group compared with $56.6 \%$ of participants in the control group, there are no significant difference between both groups $(p>.05)$. In relation marital status, this table discovered that $66.6 \%$ and $60 \%$ in the study and control group were married. whereas (6.6\% and $10.0 \%$ ) in the study and control group were single. Regarding the educational

Published by Sciedu Press level, this schedule stated that (33.3\% and $10 \%)$ were illiterate in study and control group. Referring to occupation, the most of patients in both groups (80\% and $90 \%)$ were not working.

Figure 2 illustrates percentage distribution of gender. It is clear that more than half the patients in the study and control groups $(63.0 \%$ and $60.0 \%)$ were male.

Table 2 describes medical history among study groups. It displays that most of the sample in study and control group was less than 10 years with illness. This table also shows that majority of sample in both group $(83.3 \%$ and $90 \%)$ were admission to hospital. There was no significant difference between both groups in pollution around home, smoking ( $p$ $>.05$ ).

Table 3 reveals statistically significant improvements of temperature, respiration and blood pressure (systolic, diastolic from initials to follow up condition $(p<.001)$, while there are no statistically significant improved $(p>.05)$ at BW and pulse through study phases.

Figure 3 reveals that mean anxiety improvement from pretest to follow up test (70.24, 24.65 and 28.9 respectively) in study group when compared by control group $(70.12,60.81$ and 62.87 respectively). As regard to dyspnea in the study and control group, Figure 4 shows the mean scores of dyspnea improvement from pre to post test and follow up (21.6, 8.63 and 9.82 respectively) in the study group.

Table 4 clears that there are significant correlation between anxiety and dyspnea $(p=.001)$. This attributed that improvement in anxiety leads to improvement in dyspnea.

\section{Discussion}

COPD is a group of diseases characterized by irreversible airflow obstruction and erased ability of lung to performed their ventilation and psychological disordered and poor health status. Moreover, evidence suggests that adding non pharmacological intervention such as forward leaning position and breathing exercises to improve ventilation and reduce dyspnea symptoms and psychological problems as well as better outcome. Therefore, this study was aim to evaluate the effects of positioning and pursed lip breathing exercise on dyspnea and anxiety status in patients with COPD.

The current study exposed that two third of the both groups were males. These results coincide with Castelino et al. ${ }^{[27]}$ who reported majority of your study were males (90.7\%). Similarly, Barrecheguren and colleagues ${ }^{[28]}$ stated that $76.9 \%$ of the sample was male. These result inconsistent with Raghavan et al. ${ }^{[29]}$ who conducted study "chronic obstructive pulmonary disease: the impact of gender", they found 
that women are higher prevalence as compared with male. affected equally ordinarily. ${ }^{[30]}$

In contrast to these studies, they revealed that both sex are

Table 1. Sociodemographic characteristics of patients in the study and control group

\begin{tabular}{|c|c|c|c|c|c|}
\hline \multirow{2}{*}{ Items } & \multicolumn{2}{|c|}{ Study G. } & \multicolumn{2}{|c|}{ Control G. } & \multirow{2}{*}{$\begin{array}{l}\chi^{2} \\
p \text { value }\end{array}$} \\
\hline & No & $\%$ & No & $\%$ & \\
\hline \multicolumn{6}{|l|}{ Sex } \\
\hline Male & 19 & 63.3 & 18 & 60 & \multirow{2}{*}{.68 (NS) } \\
\hline Female & 11 & 36.6 & 12 & 40 & \\
\hline \multicolumn{6}{|l|}{ Age } \\
\hline$<35$ years & 1 & 3.3 & 1 & 3.3 & \multirow{4}{*}{.149 (NS) } \\
\hline 35-44 years & 3 & 10 & 4 & 13.3 & \\
\hline 45-55 years & 10 & 33.3 & 8 & 26.6 & \\
\hline$>56$ years & 16 & 53.3 & 17 & 56.6 & \\
\hline \multicolumn{6}{|l|}{ Marital status } \\
\hline Single & 2 & 6.6 & 3 & 10 & \multirow{3}{*}{.127 (NS) } \\
\hline Married & 20 & 66.6 & 18 & 60 & \\
\hline Divorced/widowed & 8 & 26.6 & 9 & 30 & \\
\hline \multicolumn{6}{|l|}{ Educational level } \\
\hline University & 9 & 30 & 8 & 26.6 & \multirow{4}{*}{2.65 (NS) } \\
\hline Secondary & 6 & 20 & 9 & 30 & \\
\hline Read and write & 5 & 16.6 & 10 & 33.3 & \\
\hline Illiterate & 10 & 33.3 & 3 & 10 & \\
\hline \multicolumn{6}{|l|}{ Occupation } \\
\hline Not working & 24 & 80 & 27 & 90 & \multirow[t]{2}{*}{.171 (NS) } \\
\hline Working & 6 & 20 & 3 & 10 & \\
\hline
\end{tabular}
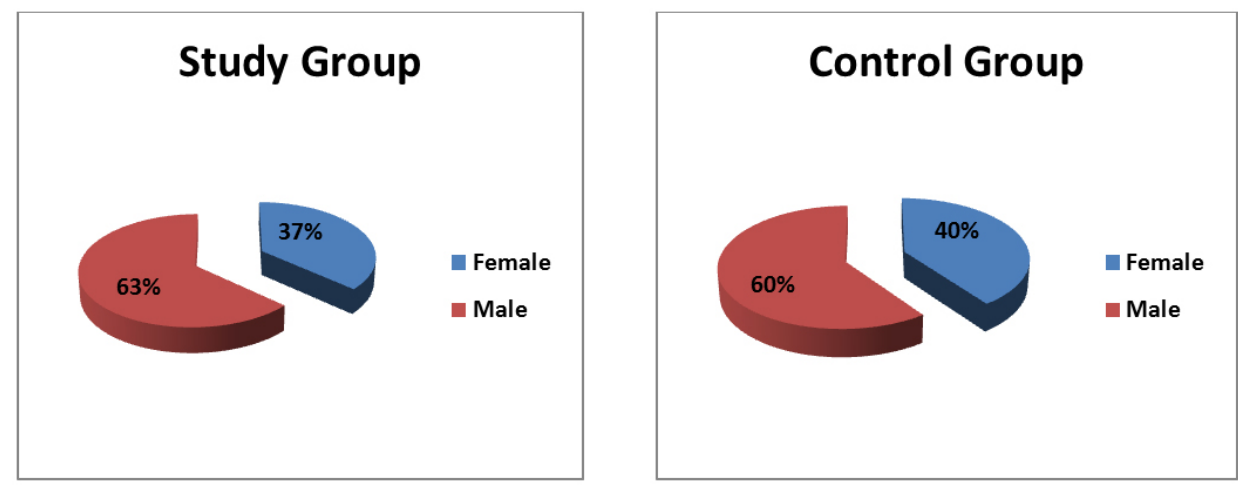

Figure 2. Percentage distribution of gender in study and control group $(\mathrm{N}=30)$

In our study, the result reveals more half of the study group compared with nearly two third of subjects in control group were aged $>56$ years old. In line with Belza et al. ${ }^{[31]}$ who revealed that study sample over 57 years of age. This finding is inconsistent with Navarro et al. ${ }^{[32]}$ showed that the most of study were age 65 years. On the other hand, pulmonary function gradually decays with advanced age may lead to of structural and physiological changes to the lung. ${ }^{[33]}$

In relation to the exposure to pollution, it was observed that most of the patients in both groups were dust source and factory pollution. In line with study of GOLD ${ }^{[34]}$ stated that outdoor pollution such as dust source and factory occupational are associated with COPD. Biofuels exposure from cooking is a leading risk factor for COPD development among 
non-smoking women, particularly in developing countries. air pollutants are well-decided risk factors for COPD exacer-

Similarity study done by DeVries ${ }^{[35]}$ revealed that outdoor bation.

Table 2. Medical history among patients in study and control group

\begin{tabular}{|c|c|c|c|c|c|}
\hline \multirow{2}{*}{ Items } & \multicolumn{2}{|c|}{ Study G. } & \multicolumn{2}{|c|}{ Control G } & \multirow{2}{*}{$\begin{array}{l}\chi^{2} \\
p \text { value }\end{array}$} \\
\hline & No & $\%$ & No & $\%$ & \\
\hline \multicolumn{6}{|l|}{ Duration of illness } \\
\hline$<10$ years & 23 & 67.6 & 25 & 83.3 & \multirow{3}{*}{0.127 (NS) } \\
\hline$>10$ years & 7 & 23.3 & 5 & 16.6 & \\
\hline$>20$ years & 0 & 0 & 0 & & \\
\hline \multicolumn{6}{|c|}{ Previous hospital admission } \\
\hline Yes & 25 & 83.3 & 27 & 90 & \multirow{2}{*}{0.527 (NS) } \\
\hline No & 5 & 16.6 & 3 & 10 & \\
\hline \multicolumn{6}{|l|}{ Exposure to Pollution } \\
\hline Dust source & 9 & 30 & 8 & 26.6 & \multirow{4}{*}{2.52 (NS) } \\
\hline Trash burning area & 2 & 6.6 & 4 & 13.3 & \\
\hline Factory & 8 & 26.7 & 7 & 23.3 & \\
\hline Gardens & 1 & 3.3 & 3 & 10 & \\
\hline \multicolumn{6}{|l|}{ Smoking } \\
\hline Smoker & 18 & 60 & 19 & 63.3 & \multirow{3}{*}{1.89 (NS) } \\
\hline Non smoker & 6 & 20 & 7 & 23.3 & \\
\hline Second hand smoker & 6 & 20 & 4 & 13.3 & \\
\hline \multicolumn{6}{|l|}{ Cough } \\
\hline Yes & 11 & 36.6 & 10 & 33.3 & \multirow[t]{2}{*}{2.31 (NS) } \\
\hline No & 19 & 63.6 & 20 & 66.6 & \\
\hline
\end{tabular}

Table 3. Comparison between Pre, Post and Follow-up scores of patients' physiological outcome among study group $(\mathrm{n}=$ 30)

\begin{tabular}{|c|c|c|c|c|}
\hline \multirow{3}{*}{ Physiological Signs } & \multicolumn{4}{|l|}{ Mean score } \\
\hline & \multirow{2}{*}{$\begin{array}{l}\text { Pre } \\
\text { Mean } \pm \text { SD }\end{array}$} & \multirow{2}{*}{$\begin{array}{l}\text { Post } \\
\text { Mean } \pm \text { SD }\end{array}$} & \multirow{2}{*}{$\begin{array}{l}\text { Follow up } \\
\text { Mean } \pm \text { SD }\end{array}$} & \multirow{2}{*}{$\begin{array}{l}\text { Paired Samples Test } \\
\text { (p-value) }\end{array}$} \\
\hline & & & & \\
\hline Body Weight & $83.23 \pm 7.31$ & $80.65 \pm 7.73$ & $81.93 \pm 8.12$ & $-0.564(>.05)$ \\
\hline \multicolumn{5}{|l|}{ Vital signs } \\
\hline Temperature & $37.10 \pm 0.40$ & $36.43 \pm 0.33$ & $36.84 \pm 0.26$ & $-6.75(<.001)^{* * *}$ \\
\hline Pulse & $81.52 \pm 5.25$ & $75.72 \pm 7.53$ & $77.43 \pm 7.22$ & $-1.49(>.05)$ \\
\hline Respiration & $20.18 \pm 2.39$ & $19.18 \pm 1.56$ & $20.62 \pm 1.38$ & $-4.27(<.001)^{* * *}$ \\
\hline \multicolumn{5}{|l|}{ Blood pressure } \\
\hline Systole & $130.12 \pm 35.4$ & $121.1 \pm 9.9$ & $120.9 \pm 10.31$ & $5.21(<.000)^{* * *}$ \\
\hline Diastole & $90.32 \pm 8.83$ & $79.1 \pm 10.6$ & $81.4 \pm 11$ & $5.87(<.001)^{* * *}$ \\
\hline
\end{tabular}

Regarding the smoking, our study found sixty percent in study group compared with sixty three in control group with on statistical significant different between them. These finding in the line with Erb-Downward and coworkers ${ }^{[36]}$ analyzed of the lung microbiome in the "Healthy" smoker on COPD among 14 patients, they found 8/14(57.14\%) were cur-

rently smoking. Previous study by Hussien ${ }^{[37]}$ also revealed that the majority of COPD patients were smoker. Buist and colleagues $^{[38]}$ reported that smoking being celebrated as its most significant causative factor for COPD patients.

In relation to coughing, it was noticed that the most of the 
study and control groups didn't coughing, while around one third both groups who complain of the cough. This finding in line with a European cross-sectional study by Kessler et al. ${ }^{[39]}$ assessed patients' perception of COPD symptom variability, they found that cough was reported by $55 \%$ of subjects with $20 \%$ rating it severe to extreme.

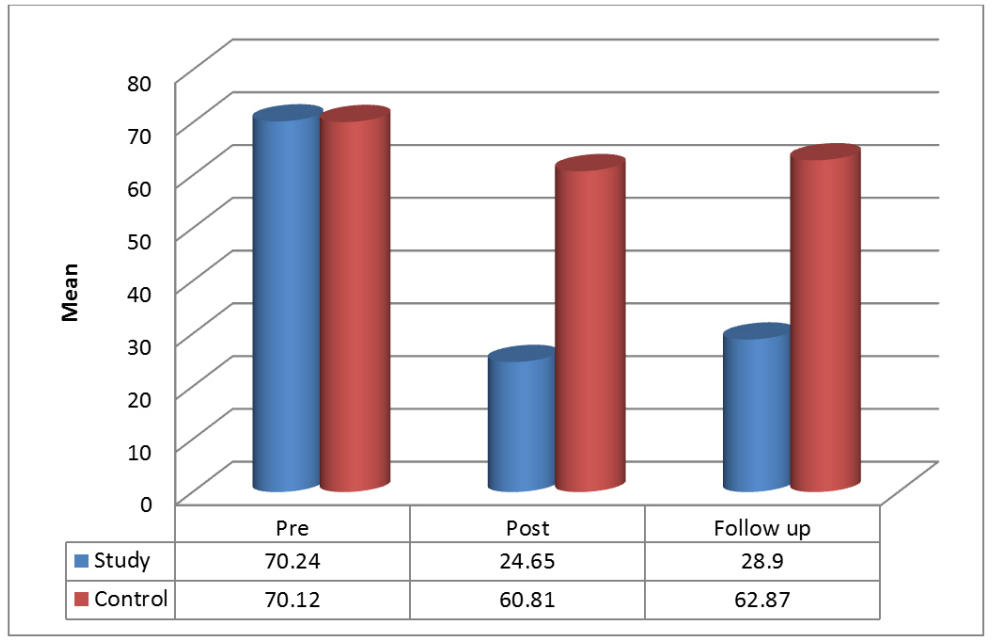

Figure 3. Distribution of anxiety level at pre, post and follow up in study group

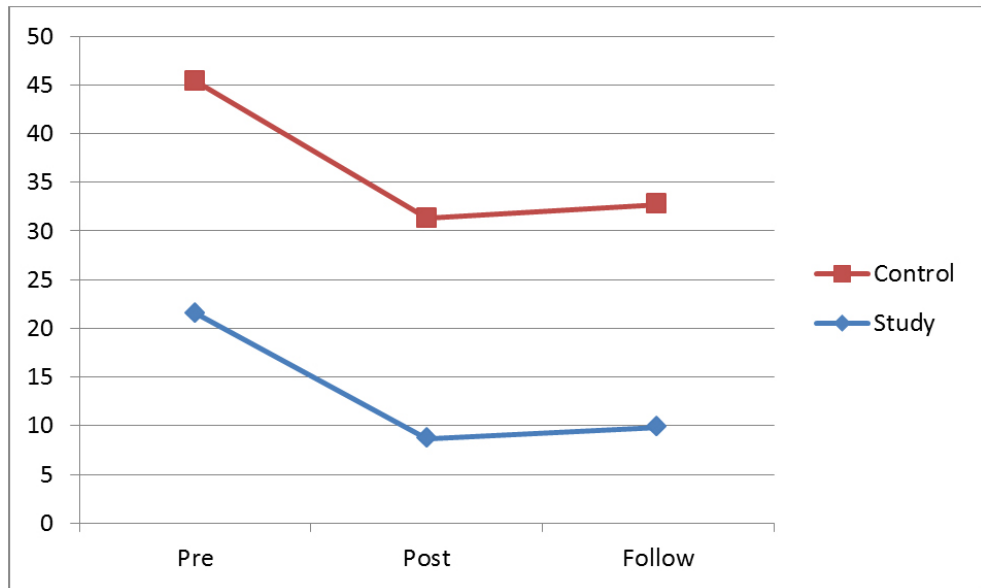

Figure 4. Distribution of patients of the study group according to mean of dyspnea at three intervals: pre, post and follow up

Table 4. Correlation between anxiety and dyspnea at Study group

\begin{tabular}{llll}
\hline \multirow{2}{*}{ Parameter } & \multicolumn{1}{l}{ Study G. } & Control G. & M-value \\
\cline { 2 - 4 } & Mean \pm S.D & Mean \pm S.D & \\
\hline Anxiety status & 73.4 & 77.54 & .001 \\
Pre & 31.8 & 45.87 & 30.45 \\
Post & 2.29 & \\
Follow up & & $2.52 \pm 0.75$ \\
Dyspnea & $2.57 \pm 0.75$ & $1.85 \pm 0.77$ & .001 \\
Pre & $1.36 \pm 0.73$ & $1.91 \pm 0.79$ & \\
Post & $1.86 \pm 0.76$ & \\
Follow up & &
\end{tabular}


The results of this study revealed that highly statistically significant difference between study and control groups as regard to blood pressure, heart rate and respiration rate mean scores after implementation of program. In agreement with our results, Bhatt et al. ${ }^{[40]}$ studied the impact of Pursed lips breathing (PLB) on exercise capacity in patients with stable COPD. The intervention in the Crossover study were comparing 6-min walk test with and without PLB. They found decrease in the respiratory rate (RR) after exercise with PLB and improve exercise capacity. Jones et al. ${ }^{[41]}$ reported that $\mathrm{BP}$ levels among patients lower than $\mathrm{BP}$ readings prior to exercise.

The study results revealed that statistically significant improvement in the present study group when compared with control groups as regard to dyspnea. This might be attributed to physical exercise (pursed lips exercise and positioning) enhances or maintains physical fitness, respiration and decrease deterioration of condition during attack as well as improved overall health. These result congruent with El Hoshy, Eshmawey and Tawab ${ }^{[42]}$ who stated that a significant statistically significant improvement in the present study after exercise program in COPD patient when compared with control group that received an unstructured program. In line with Lacasse et al. ${ }^{[43]}$ who showed that strengthen respiratory muscle, reduce symptoms dyspnea as well as better quality of life after application of exercise training. von Leupoldt et al. ${ }^{[44]}$ also indicated that dyspnea betterment during pulmonary rehabilitation is compatible with a decrease in experience of noxious emotions.

El-Sousai ${ }^{[45]}$ also showed that there was significant improvement in lung functions post breathing exercise. This supported with previous study done by Mohamed ${ }^{[46]}$ who showed that most of patients used sitting positioning to reduce dyspnea. On the other hand, Retrospective, observational study by Van Ranst and coworkers ${ }^{[47]}$ in The Netherlands among 437 patients with COPD who exposure to program for 3 months for a weekly with average of 20-25 hours/weekly, assessed the patients before and after intervention, found improved health status outcome $(p<.001)$.

Regarding physiological outcome such as anxiety difference

\section{REFERENCES}

[1] Gobal initiative for chronic obstructive lung disease (GOLD). Global strategy for the Diagnosis, Management and Prevention of chronic obstructive pulmonary disease [homepage on the Internet]. 2017 report. Available from: http://www.goldcopd.com

[2] Lumb A, Biercamp C. Chronic obstructive pulmonary disease and among the studied COPD, there was statistically significant improvement of anxiety and tension reduce after implementation of program. This may be attributed to rehabilitation program had positive effect on patient's psychosocial status and physical functioning. This result agrees with Valenza et al. ${ }^{[48]}$ who revealed that statistical significant related to 10 psychological variables in the intervention group after controlled breathing program and significant deterioration in the control group only on hospital routine.

The results of the current study indicated that, there was a significant statistically correlation between dyspnea and anxiety status in studied group. This finding in lines with work of Neuman et al. ${ }^{[49]}$ who indicated that psychological status is a significant factor to consider when treating patients that have dyspnea in clinical setting. On the other hand, the presence of respiratory symptoms leads to significant dyspnea was correlated significantly with anxiety and depression in these patients. This finding in constant with study by de Voogda ${ }^{[50]}$ among 90 patients with stable COPD, they investigated that general anxiety was associated with dyspnea on exertion COPD $(p<.00)$.

\section{CONCLUSION AND RECOMMENDATIONS}

Based on the outcomes of research finding, it is noticed that the pursed lip breathing exercise and dyspnea positioning techniques display significant improvement in physiological outcome, improve symptoms of breathlessness and strengthening respiratory muscle. The rehabilitation program could be helpful in improving psychological status of COPD patients. Also the program is significant for enhancing knowledge of the COPD patients. Based these results it is recommended to established this program as a routine care in clinical setting when provide management for COPD.

Our study was limited by the study conducted at the one geographical area in which there were few number of chronic obstructive pulmonary disease who included inclusion criteria. Also, small number of the sample led to inability to generalizability the finding of the study.

\section{CONFLICTS OF INTEREST Disclosure}

The author declared no conflicts of interest. anaesthesia. Continuing Education in Anaesthesia Critical Care \& Pain. 2014; 14(1): 1-5.

[3] Liang J, Liu L, Fang QH. Clinical characteristics of patients with chronic obstructive pulmonary disease overlapped with bronchial asthma. Annals of Allergy, Asthma \& Immunology. 2017; 118(5): 564-569. 
[4] Cielen N, Maes K, Gayan-Ramirez G. Musculoskeletal disorders in chronic obstructive pulmonary disease. Biomed Res Int. 2014; 9657-9664.

[5] Decramer M, Janssens W, Miravitlles M. Chronic obstructive pulmonary disease. Lancet. 2012; 379(9823): 1341-1351.

[6] Stockley RA. Bronchiectasis with chronic obstructive pulmonary disease association or a further phenotype?. American Journal of Respiratory and Critical Care Medicine. 2013.

[7] Güell MR, Cejudo P, Ortega F, et al. Benefits of long-term pulmonary rehabilitation maintenance program in patients with severe chronic obstructive pulmonary disease. Three-year follow-up. Am J Respir Crit Care Med. 2017; 195(5): 622-629.

[8] Lenferink A, Brusse-Keizer M, van der Valk PD, et al. Selfmanagement interventions including action plans for exacerbations versus usual care in patients with chronic obstructive pulmonary disease. Cochrane Database Syst Rev. 2017 Aug 4; 8.

[9] Hayen A, Herigstad M, Pattinson KTS. Understanding dyspnea as a complex individual exeprience. Maturitas. 2013; 76(1): 45-50.

[10] Sahasrabudhe TR. Psychogenic dyspnea. Medical Journal. 2013; 6(1): 14-18.

[11] Mark C. COPD significantly reduces health-related quality of life Respir. Med. 2011; 105: 57-66.

[12] Leivseth L, Nilsen TL, Mei Mai X, et al. Lung function and anxiety in association with dyspnoea: The HUNT study. Respiratory Medicine. 2012; 106: 1148-1157.

[13] Huang TY, Moser DK, Hsieh YS, et al. Moderating effect of psychosocial factors for dyspnea in Taiwanese and American heart failure patients. J Nurs Res. 2013; 21(1): 49-58.

[14] Yohannes AM, Junkes-Cunha M, Smith J, et al. Management of Dyspnea and Anxiety in Chronic Obstructive Pulmonary Disease: A Critical Review. JAMDA. 2017; 18(12): 1096.e1-1096.e17.

[15] Harris M, Smith BJ, Veale A. Patient education programs - can they improve outcomes in COPD?. Int J Chron Obstruct Pulmon Dis. 2008; 3(1): 109-112.

[16] Kim K, Byun MK, Won-hwee Lee WH, et al. Effect of breathing maneuver and sitting posture on muscle activity in inspiratory accessory muscles in patients with chronic obstructive pulmonary disease. Multidiscip Respir Med. 2012; 7(1): 9.

[17] Prasad SA, Pryor JA. Physiotherapy for Respiratory and Cardiac Problems Adults and Paediatrics. Edinburgh: Churchill Livingstone Elsevier. 2010; 5: 319-326.

[18] Lewis R, Heitkemper M, Dirksen S. Medical surgical nursing: Assessment and Management of Clinical Problems, 9th Ed. Mosby Yearbook, USA. 2013; 660-671.

[19] Cabral LF, D'Elia CT, Marins Dde S, et al. Pursed lip breathing improves exercise tolerance in COPD: a randomized crossover study. Eur J Phys Rehabil Med. 2015 Feb; 51(1): 79-88.

[20] McGee S. Pursed Lip Breathing. Evidence-Based Physical Diagnosis; In Chapter 33 - Chronic Obstructive Lung Disease; Fourth Ed. Elsevier; 2018; 285-290.

[21] Zwerink M, Brusse-Keizer M, van der Valk PD, et al. Self management for patients with chronic obstructive pulmonary disease. Cochrane Database Syst Rev. 2014.

[22] Blackstock FC, Lareau SC, Nici L, et al. Chronic Obstructive Pulmonary Disease Education in Pulmonary Rehabilitation. An Official American Thoracic Society/Thoracic Society of Australia and New Zealand/Canadian Thoracic Society/British Thoracic Society Workshop Report. 2018.

[23] Liang J, Abramson JM, Johnson George J. Educational interventions for health professionals managing COPD in primary care. Cochrane Systematic Review. 2017. Available from: https://www . cochra nelibrary.com/cdsr/doi/10.1002/14651858
[24] World Health Organization (WHO). Noncommunicable diseases country profiles. Geneva: World Health Organization. 2011.

[25] Borg G. Psychophysical bases of perceived exertion. Medicine and Science in Sports and Exercise. 1982; 14(5): 377-81.

[26] Zung WW. The measurement of affects: depression and anxiety. Mod Probl Pharmacopsychiatry. 1974.

[27] Castelino F, Prabhu M, Shivananda Pai M, et al. Socio-demographic and clinical characteristics of Chronic Obstructive Pulmonary Disease (COPD) patients. Manipal Journal of Nursing and Health Sciences. 2017; 3(2): 55-58.

[28] Barrecheguren M, Monteagudo M, Miravitlles M. Populationbased study of LAMA monotherapy effectiveness compared with LABA/LAMA as initial treatment for COPD in primary care. Primary Care Respiratory Medicine. 2018.

[29] Deepa R, Varkey A, Bartter T. Chronic obstructive pulmonary disease: the impact of gender. Current Opinion in Pulmonary Medicine. 2017; 23(2): 117-123.

[30] WHO. Chronic obstructive pulmonary disease (COPD) Fact sheet 315 WHO. January 2015. 2016.

[31] Belza B, Steele BG, Hunziker J, et al. Correlates of physical activity in chronic obstructive pulmonary disease. Nurs Res. 2001; 50(4): 195-202.

[32] Navarro CLJ, Medina PAM, Tárraga López JP, et al. Quality of Life in Patients with Chronic Obstructive Pulmonary Disease in the Province of Albacete (Spain). Chest Journal. 2014.

[33] Devereux G. ABC of chronic obstructive pulmonary disease: Definition, epidemiology, and risk factors. British Medical Journal. 2006; 332: 1142-1144.

[34] Global Initiative for Chronic Lung Disease (GOLD). Global Strategy for Diagnosis, Management and Prevention of Chronic Obstructive Pulmonary Disease. 2014.

[35] DeVries R. Short term effects of outdoor air pollution on respiratory health in susceptible populations (Doctoral dissertation). University of Massachusetts Lowell. 2015.

[36] Erab-Dwanword JR, Thompson D, Han MK, et al. Analysis of the lung microbiome in the "Healthy" smoker and in COPD. 2011.

[37] Hussein J. Prevalence of smoking amongst Mou,ta University Employees in Al-kerak, Jordon. The New Egyptian Journal of Medicine. 2004; 31(2): 147-150

[38] Buist AS, Vollmer WM, McBurnie MA. Worldwide burden of COPD in high- and low-income countries. Part I. The Burden of Obstructive Lung Disease (BOLD) Initiative. Int. J. Tuberc. Lung Dis. 2008; 12: 703-708.

[39] Kessler R, Partridge MR, Miravitlles M, et al. Symptom variability in patients with severe COPD: a panEuropean cross-sectional study. Eur Respir J. 2011; 37(2): 264-72.

[40] Bhatt SP, Luqman-Arafath TK, Gupta AK, et al. Volitional pursed lips breathing in patients with stable chronic obstructive pulmonary disease improves exercise capacity. Chronic Respiratory Disease. 2012; 10(1): 5-10.

[41] Jones CU, Sangthong B, Pachirat O, et al. Slow breathing training reduces resting blood pressure and the pressure responses to exercise. Physiological Research. 2015; 64: 673-682.

[42] El Hoshy SM, Eshmawey AH, El Tawab SS. Outcome of pulmonary rehabilitation in patients with COPD: Comparison between patients receiving exercise training and those receiving exercise training and CPAP. Egyptian Journal of Chest Diseases and Tuberculosis. 2017; 66(2017): 609-616.

[43] Lacasse Y, Martin S, Lasserson TJ, et al. Meta-analysis of respiratory rehabilitation in chronic obstructive pulmonary disease. A Cochrane systematic review. Eura Medicophys. 2007; 43(4): 475-485. 
[44] von Leupoldt A, Taube K, Lehmann K, et al. The impact ofanxiety and depression on outcomes of pulmonary rehabilitation in patientswith COPD. Chest. 2011; 140(3): 730-6.

[45] El-Sousai IA. Responses of ventilator functions to breathing exercise versus breathing exercises with chest mobilizing exercises in elderly. Unpublished Master Thesis. Faculty of physical therapy, Cairo University, Egypt. 2008.

[46] Mohamed A. Measures used by patients with chronic obstructive pulmonary disease to manage the sensation of dyspnea. 2001.

[47] van Ranst D, Stoop WA, Meijer JW, et al. Reduction of exacerbation frequency in patients with COPD after participation in a comprehen- sive pulmonary rehabilitation program. Int J Chron Obstruct Pulmon Dis. 2014 Oct 3; 9: 1059-67.

[48] Valenza MC, Valenza-Peña G, Torres-Sánchez I, et al. Effectiveness of controlled breathing techniques on anxiety and depression in hospitalized patients with COPD: a randomized clinical Trial. Respir Care. 2014; 59(2): 209-15.

[49] Neuman A, Gunnbjörnsdottir M, Tunsäter A, et al. Dyspnea in relation to symptoms of anxiety and depression: A prospective population study. Respir Med. 2006; 100(10): 1843-9.

[50] de Voogda JN, Sandermanb R, Postemaa K, et al. Relationship between anxiety and dyspnea on exertion in patients with chronic obstructive pulmonary disease. Anxiety, Stress, \& Coping. 2010. 